\title{
TINJAUAN FATIK ELEMEN STRUKTUR ATAS JEMBATAN TERHADAP LHR DAN USIA RENCANA SESUAI AASHTO 2012
}

\author{
Fauzri Fahimuddin ${ }^{1}$, Dio Akbar Hakim ${ }^{2}$, Andi Indiandto ${ }^{3}$ \\ 1,2,3 Jurusan Teknik Sipil Politeknik Negeri Jakarta Jl. Prof.Dr.G.A.Siwabessy, Kampus UI Depok 16425 \\ fauzri.fahimuddin@sipil.pnj.ac.id,dioakbar21@gmail.com,andipnj@gmail.com
}

\begin{abstract}
A lot of structures failure on the bridge, causes a collapsed to the bridges. The reason of the collapsed was dynamic loads that happen on the bridge. Dynamic loads make stress and relax happen at the same time. Fatigue analysis is an analysis that calculate the dynamic load that happen on the bridge, with counting the big vehicle or truck. Fatigue analysis can't analyze all the element with one step. In this research the bridge was a truss bridge with span $70 \mathrm{~m}$ as the main structure. In fatigue analysis, stress that used was stress that caused by dead load and stress that caused by the big vehicle or truck passing through. The value between that stresses used to call stress range. In AASHTO the value of truck that passing truck in a traffic called Average Daily Truck Traffic (ADTT). Stringer, cross beam, and main truss was the element that will be analyzed. In this structure we use category B, where ADTT is 860, Threshold is $110 \mathrm{MPa}, \mathrm{A}$ is $39,3 \times 1011$, and the $n$ is 1. From stress range that happen in the structure, we can find the age and ADTT until the bridge collapse because fatigue. In the end the elements that had the lowest age and the lowest ADTT was the main truss, where it just has 27 years old left and can only take 299 truck/day. Then the bridge has to get a maintenance and repair before it gets 27 years old.
\end{abstract}

Keywords : Fatigue, age, ADTT, stress range

\begin{abstract}
ABSTRAK
Banyak terjadinya kegagalan struktur pada jembatan, yang menyebabkan keruntuhan pada jembatan. Hal itu disebabkan oleh beban dinamis yang terjadi pada jembatan. Beban dinamis membuat terjadinya tegangan dan relaksasi dalam waktu bersamaan. Analisa fatik merupakan perhitungan dengan memperhitungkan beban dinamis yang terjadi pada jembatan, dengan beban dianggap sebagai kendaraan besar atau truk. Memperhitungkan kondisi fatik tidak dapat dihitung langsung untuk satu jembatan. Dalam analisa ini menggunakan jembatan dengan bentang $70 \mathrm{~m}$ sebagai struktur rangka atasnya. Pada Analisa fatik tegangan yang dihitung berupa tegangan akibat beban sendiri pada jembatan dan tegangan ketika dilalui oleh kendaraan besar atau truk. Perbedaan tegangan tersebut biasa disebut dengan stress range. Pada AASHTO, lalu lintas harian rata-rata (LHR) biasa disebut Average daily truck traffic (ADTT). Elemen yang dihitung berupa stringer, cross beam, dan batang rangka utama. Pada struktur ini kategori yang digunakan adalah kategori B dengan ADTT sebesar 860, threshold sebesar 110 MPa, A sebesar 39,3 x 1011 MPa3 dan $n$ sebesar 1. Dari stress range yang didapat, maka dapat dicari umur jembatan serta ADTT hingga jembatan pada kondisi fatik. Dapat disimpulkan bahwa elemen yang mempunyai umur dan ADTT terendah adalah batang rangka utama, dengan nilai umur rencana 27 tahun dan ADTT 299 truk/hari. Dengan demikian dapat dinyatakan bahwa jembatan harus diberi perkuatan saat umur mendekati 27 tahun.
\end{abstract}

Kata kunci : Fatik, umur rencana, ADTT, stress range.

\section{PENDAHULUAN}

\section{Latar Belakang}

Beban kendaraan yang melintas pada jembatan memberikan efek beban pada elemen yang menimbulkan terjadinya tegangan kemudian relaksasi ketika kendaraan telah melintas dan kemudian timbul tegangan kembali saat ada kendaraan selanjutnya melintas dan 
relaksasi kembali, dan akan terus berulang hingga masa layan jembatan.

Walaupun tegangan ini tidak selamanya ada, jika terus berulang dalam waktu yang lama dapat menimbulkan retak dan patah pada bagian tertentu (Barker and Puckett 2007).

Pembebanan berulang walaupun tidak melampaui titik leleh dapat mengakibatkan keruntuhan. Fenomena ini disebut fatik atau kelelahan. Kelelahan dapat terjadi walaupun semua kondisinya ideal, yaitu kelihatan takiknya baik, tidak ada konsentrasi tegangan akibat lubang atau takik, kondisi tegangan uni-aksial, mikrostruktur daktil, dan sebagainya. (Salmon, 1980).

Analisa fatik adalah salah satu perhitungkan yang meninjau tentang kelelahan dan keruntuhan struktur. Melalui perhitungan dengan menggunakan volume kendaraan dan juga perubahan tegangan yang terjadi pada jembatan.

Dengan merencanakan analisa fatik, jembatan bisa diperkirakan dapat menahan keruntuhan jembatan dan juga keretakan pada elemen. Perhitungan fatik yang digunakan sesuai dengan AASHTO LRFD Bridge Design Spesification 2012.

\section{Tujuan Penelitian}

1. Mengidentifikasi umur rencana dan jumlah volume kendaraan truk sesuai peraturan AASHTO LRFD Bridge Design Spesification 2012

2. Mengidentifikasi perbedaan desain dengan analisa fatik menggunakan peraturan AASHTO LRFD Bridge Design Spesification 2012 dan desain tanpa analisa fatik dengan menunjukan hasil akhir berupa dimensi dari perbedaan desain dengan analisa fatik dengan desain tanpa analisa fatik.

\section{Tinjauan Pustaka}

\section{Fatik}

Fatik atau kelelahan merupakan fenomena terjadinya kerusakan material karena pembebanan yang berulangulang, diketahui bahwa apabila pada suatu logam dikenai tegangan berulang maka logam tersebut akan patah pada tegangan yang jauh lebih rendah dibandingkan dengan tegangan yang dibutuhkan untuk menimbulkan perpatahan pada beban statik.

Kerusakan akibat beban berulang ini disebut patah lelah (fatigue failures) karena umumnya perpatahan tersebut terjadi setelah periode pemakaian yang cukup lama.

Hal-hal yang mempengaruhi dalam perencanaan menggunakan analisa fatik adalah:

a. LHR (lalu lintas harian rata-rata) untuk kendaraan truk atau ADTT (average daily truck traffic) dalam suatu daerah yang akan dibangun jembatan, yang akan memengaruhi nilai siklus.

b. Panjang struktur elemen pada jembatan. Semakin panjang elemen yang digunakan akan membuat fluktuasi akibat beban truk semakin besar.

c. Besar kecilnya dimensi struktur yang dipakai, serta beban tetap yang ditanggung oleh struktur tersebut. Hal ini dapat memperngaruhi tegangan yang terjadi pada beban saat tidak ada kendaraan dan itu dapat berpengaruh terhadap stress range.

d. Tipe sambungan yang digunakan pada struktur jembatan. 


\section{Kategori Detail}

Kategori detail digunakan untuk mengelompokkan komponen dan bagian detail yang mudah dipengaruhi oleh beban fatik berdasarkan daya tahan fatik masing-masing (Barker, 2007).

Detail yang tidak diklasifikasi harus dianggap sebagai kategori detail paling rendah dari detail serupa, kecuali dapat dibuktikan dengan pengujian atau analisis dan pengujian bahwa kekuatan fatiknya lebih besar.

Kategori tergantung pada detail sambungan yang direncanakan. Nilai dari kategori terdapat pada AASHTO LRFD: Bridge Design Spesification 2012.

Kategori terbagi menjadi 8 kategori. Masing-masing kategori memiliki tahanan fatik yang berbeda. Yaitu A, B, B', C, D, E, dan E', yang dimana semakin rendah kategori semakin kecil tahanan fatiknya.

Pengalaman mengindikasikan bahwa dalam proses perencanaan pertimbangan fatik untuk kategori detail A sampai B' sangat jarang. Namun demikian, kategori detail A sampai B' tetap dimasukan dalam tabel kategori detail untuk melengkapi. Investigasi untuk kategori detail A sampai B' mungkin digunakan untuk pembanguna $\mathrm{n}$ dalam kasus-kasus khusus.

\section{Analisa Fatik}

Analisa fatik memperhitungkan stressrange yang terjadi pada jembatan. Stress-range tersebut adalah perbedaan tegangan saat dengan bebean mati dan tegangan saat truk melintas.

Stress range tersebut harus lebih kecil dari stress range nominal yang disyaratkan. (AASHTO LRFD Bridge Design Spesification 2012). Didalam perhitungan digunakan notasi-notasi sebagai berikut:

$\Delta$ : Faktor keamanan untuk fatik (Fatik-I: 1,5 \& Fatik-II: 0,75)

$(\sigma) \quad$ : Stress range $(\mathrm{Mpa})$

$(\sigma) \mathrm{n}:$ Stress range nominal untuk fatik (Mpa)

Stress range merupakan perbedaan tegangan pada saat kondisi kosong dan saat dilalui oleh beban dinamis, karena kondisi fatik dianggap terjadi saat kondisi fluktuasi akibat truk melintas.

\section{Fatik II}

Fatik II adalah finite fatigue life, yang dimana stress range dapat diperhitungkan berdasarkan populasi kendaraan truk dan umur rencana.

Dalam kondisi ini diasumsikan elemen akan mengalami fatik dengan umur rencana tertentu. (AASHTO LRFD Bridge Design Spesification 2012). Didalam perhitungan digunakan notasinotasi sebagai berikut:

$(\sigma) \mathrm{n}:$ Stress range nominal fatik (MPa)

$\begin{array}{llr}\text { A } & \text { : konstan } & \text { kategori } \\ & \text { sambungan }\left(\mathrm{MPa}^{3} / \mathrm{ksi}^{3}\right)\end{array}$

$\mathrm{N}$ : Jumlah dari siklus stress range sesuai kendaraan

Nilai $\mathrm{N}$ adalah siklus yang diperhitungkan berdasarkan banyaknya truk yang melintas pada satu jalur.

Dalam studi ini perhitungan dilakukan dengan memperkirakan umur rencana selama 75 tahun (AASHTO LRFD Bridge Design Spesification 2012).

\section{Fatik I}

Fatik-I atau infinite load-induced fatigue life adalah kondisi dimana dianggap 
beban rencana akan membuat retakan. Pada fatik-I Stress range nominal dianggap sama dengan threshold. (AASHTO LRFD Bridge Design Spesification 2012).

Threshold merupakan batas stress range pada struktur. Besarnya threshold tergantung pada kategori. Jika stress range rencana melewati batas threshold maka jembatan akan mengalami fatik, dimana artinya jembatan akan mengalami keruntuhan.

Jika stress range rencana memenuhi syarat threshold elemen dianggap tidak akan mengalami fatik dalam jangka waktu yang sangat panjang.

Dari (AASHTO LRFD Bridge Design Spesification 2012) maka bisa diartikan sebagai berikut:

Besarnya threshold tergantung sesuai dengan kategori dari suatu struktur dan sambungannya. Dimana artinya stress range akibat beban sendiri dan beban truk, tidak boleh melampaui threshold. Nilai-nilai threshold tersebut didapatkan dari data statistik hasil pengujianpengujian sebelumnya.

\section{METODE PENELITIAN}

\section{Pemodelan Struktur}

Pemodelan struktur berupa memodelkan bentuk struktur yang akan direncanakan untuk dibebani agar menghasilkan gayagaya dalam. Pemodelan struktur yang dipakai menggunakan aplikasi SAP2000.

\section{Pembebanan}

Pembebanan didapat dari nilai berat jenis dengan luasan atau volume suatu material untuk beban struktur sendiri. Untuk beban lalu lintas tergantung pada lebarnya jalur lalu lintas. Pembebanan yang direncanakan sesuai dengan SNI
1725-2016 dan RSNI T-03-2005. Menghitung pembebanan dengan cara mengalikan tributary area dengan berat jenis suatu struktur.

Pembebanan yang dilakukan adalah pembebanan dengan metode LRFD dimana beban dikalikan dengan faktor beban, serta untuk kondisi fatik beban yang dimasukan adalah beban truk dan beban sendiri, untuk mencari perbedaan tegangan yang terjadi.

\section{Penentuan Kategori}

Penentuan kategori tergantung pada detail sambungan. Penentuan guna mendapatkan nilai-nilai yang dibutuhkan untukk merencanakan fatik. Kategori yang dipakai tercantum pada AASHTO LRFD Bridge Design Spesification 2012.

\section{Analisa Kondisi Fatik}

Pada analisa ini perhitungan yang digunakan sesuai dengan AASHTO dengan mengecek kondisi pada fatik I dan fatik II.

Pengecekan dilakukan pada setiap elemen jembatan, hal ini dikarenakan Analisa fatik tidak bisa diperhitungkan pada seluruh komponen jembatan sekaligus.

Perhitungan pada analisa fatik berupa perhitungan tegangan pada elemen yang nantinya akan menghasilkan stress range. Dimana pada Analisa dianggap elemen jembatan menerima perubahan tegangan ketika jembatan kosong dan jembatan dilalui oleh kendaraan besar (truk).

Besarnya nilai tegangan dipengaruhi oleh dimensi yang dipakai pada elemen jembatan tersebut. 


\section{HASIL dan PEMBAHASAN}

\section{Fatik Pada Stringer}

Perencanaan menggunakan kategori B susai dengan gambar 4.5-1 Dengan threshold sebesar $110 \mathrm{MPa}$, nilai konstanta A 39,3 (MPa) ${ }^{3}$, nilai ADTT sebesar 860 , nilai $\mathrm{n}=1$.

Pada fatik-I Stress range nominal dianggap sama dengan threshold. Threshold yang diketahui untuk kategori pada stringer adalah $110 \mathrm{MPa}$.

Pada kondisi fatik I memiliki $=1,5$. Maka jika kita control pada analisa kondisi fatik I: $150,489 \leq 110 \mathrm{MPa} \rightarrow$ Tidak memenuhi.

Fatik II adalah finite fatigue life, yang dimana stress range nominal diperhitungkan berdasarkan populasi kendaraan.

Pada kondisi fatik II besarnya nilai fatik nominal ditentukan melalui rumus. Pada kondisi fatik I memiliki $=0,75$. Maka jika kita control pada analisa kondisi fatik II: 75,24 $\leq 55,07 \rightarrow$ Tidak Memenuhi.

\section{Fatik Pada Cross Beam}

Perencanaan menggunakan kategori B yang terdapat pada gambar 4.5-1 Dengan threshold sebesar $110 \mathrm{MPa}$, nilai konstanta A 39,3 (MPa) ${ }^{3}$, nilai ADTT sebesar 860 , nilai $n=1$.

Pada fatik-I Stress range nominal dianggap sama dengan threshold. Threshold yang diketahui untuk kategori pada stringer adalah $110 \mathrm{MPa}$.

Pada kondisi fatik I memiliki $=1,5$. Maka jika kita control pada analisa kondisi fatik I: $70,63 \leq 110 \mathrm{MPa} \rightarrow$ Memenuhi.
Fatik II adalah finite fatigue life, yang dimana stress range nominal diperhitungkan berdasarkan populasi kendaraan.

Pada kondisi fatik II besarnya nilai fatik nominal ditentukan melalui rumus. Pada kondisi fatik I memiliki $=0,75$. Maka jika kita control pada analisa kondisi fatik II: $35,31 \leq 55,07 \rightarrow$ Memenuhi.

\section{Fatik Pada Rangka Utama}

Kategori yang dipakai dalam menganalisa Fatik untuk rangka adalah kategori B yang tercantum pada gambit 4.5-2

Dengan Threshold sebesar $110 \mathrm{MPa}$, nilai konstanta A $39,3(\mathrm{MPa})^{3}$, nilai ADTT sebesar 860, nilai $n=1$.

Pada fatik-I Stress range nominal dianggap sama dengan threshold. Threshold yang diketahui untuk kategori pada stringer adalah $110 \mathrm{MPa}$.

Pada kondisi fatik I memiliki $=1,5$. Maka jika kita control pada analisa kondisi fatik I: $156,69 \leq 110 \mathrm{MPa} \rightarrow$ Tidak Memenuhi.

Fatik II adalah finite fatigue life, yang dimana stress range diperhitungkan berdasarkan populasi kendaraan.

Pada kondisi fatik II besarnya nilai fatik nominal ditentukan melalui rumus. Pada kondisi fatik I memiliki $=0,75$. Maka jika kita control pada analisa kondisi fatik II: $78,34 \leq 55,07^{\rightarrow}$ Tidak Memenuhi.

\section{Pergantian Dimensi Stringer}

Jika tetap digunakan profil IWF $450 \mathrm{x}$ 200, jembatan akan mengalami kondisi fatik pada umur 30 tahun dengan ADTT sebesar 860, atau jembatan akan mampu menahan kondisi fatik hingga umur 75 tahun jika ADTT sebesar 338. 
Untuk menggatasi kondisi yang tidak memenuhi dalam analisa pendekatan fatik, maka diperlukan diperbesarnya dimensi pada struktur.

Dengan mecoba perhitungan dengan menggunakan profil IWF $600 \times 200$ maka didapatkan stress range $(\Delta)$ sebesar 57,74 N/mm². Maka diperlukan kembali analisa terhadap fatik I dan fatik II.

\section{Pergantian Dimensi Rangka Utama}

Jika digunakan batang rangka dengan $H$ beam 532 x 490, jembatan akan mengalami kondisi fatik pada umur 27 tahun dengan ADTT sebesar 860, atau jembatan akan mampu menahan kondisi fatik hingga umur 75 tahun jika ADTT sebesar 299 truk/hari.

Agar dapat memenuhi kondisi fatik maka dimensi rangka harus diperbesar. Digunakan H-beam 532 x 490 agar bisa menahan. Dengan nilai stress range sebesar $65,12 \mathrm{~N} / \mathrm{mm}^{2}$.

\section{Analisa Umur dan Volume kendaraan}

Setelah dilakukan perhitungan dengan analisa fatik II, Hasil analisa terhadap umur jembatan dengan LHR tanpa fatik adalah sebagai berikut.

Tabel 1. Hasil Analisa

\begin{tabular}{ccc}
\hline \multirow{2}{*}{ Struktur } & \multicolumn{2}{c}{ Kondisi Fatik } \\
\cline { 2 - 3 } & $\begin{array}{c}\text { Umur dengan } \\
\text { kondisi } \\
\text { ADTT 860 } \\
\text { truk/hari }\end{array}$ & $\begin{array}{c}\text { ADTT dengan } \\
\text { umur } \\
\text { rencana 75 } \\
\text { tahun }\end{array}$ \\
\hline Stringer & 30 tahun & 338 truk/hari \\
Cross & 285 tahun & 3263 truk/hari \\
Beam & 27 tahun & 299 truk/hari \\
Rangka & . \\
\hline
\end{tabular}

\section{KESIMPULAN}

Setelah dilakukan berbagai analisa dapat disimpulkaan bahwa:

1. Dapat disimpulkan bahwa jembatan aman hingga umur 75 tahun jika ADTT sebesar 299 truk sehari, atau jembatan mampu menahan ADTT sebesar 860 hingga umur 27 tahun.

2. Hasil perbedaan dimensi antara desain non fatik dan desain dengan fatik.

Tabel 2. Perbedaan Dimensi

\begin{tabular}{ccc}
\hline \multirow{2}{*}{ Struktur } & \multicolumn{2}{c}{ Dimensi } \\
\cline { 2 - 3 } & Non Fatik & Dengan Fatik \\
\hline \multirow{2}{*}{ Stringer } & IWF 450 x & IWF 600 x \\
Cross & 200 & 200 \\
Beam & 300 & IWF 700 x \\
Rangka & H-beam 428 x & H-beam 532 x \\
& 407 & 490 \\
\hline
\end{tabular}

Dapat disimpulkan bahwa perbedaan dimensi terjadi pada stringer dan batang rangka utama, dikarenakan tidak memenuhi syarat pada perencanaan kondisi fatik I \& fatik II.

\section{DAFTAR PUSTAKA}

[1] AASHTO, 2012. AASHTO LRFD Bridge Design Spesification. American Association of State Highway and Transportations Official, Washington, Amerika Serikat.

[2] Pusat Litbang Jalan dan Jembatan. 2016. Pembebanan Untuk Jembatan. SNI 1725-2016. Badan Standarisasi Nasional BSN, Jakarta.

[3] Pusat Litbang Prasarana Transportasi. 2005. Perencanaan Struktur Baja Untuk Jembatan. RSNI 
T-03-2005. Badan Standarisasi Nasional BSN, Jakarta.

[4] Barker, R.M., J.A Puckett. 2007. Design of Highway Bridges. John Wiley \& Sons, Inc, New York.

[5] Gurney, T. R. 1992. Fatigue Design, in Design of Highway Bridges. Barker et al. John Wiley \& Sons, Inc, New York.

[6] Salmon, C.G. \& J.E Johnson. 1980. Struktur Baja: Desain dan Perilaku. Erlangga, Jakarta. 
Fauzri Fahimuddin dkk, Tinjauan Fatik Elemen 